九州大学学術情報リポジトリ

Kyushu University Institutional Repository

\title{
Rapid synthesis of Ag@Ni core-shell nanoparticles using a microwave-polyol method
}

\section{Tsuji, Masaharu}

Department of Applied Science for Electronics and Materials, Graduate School of Engineering Sciences, Kyushu University

Hikino, Sachie

Institute for Materials Chemistry and Engineering, Kyushu University

Matsunaga, Mika

Institute for Materials Chemistry and Engineering, Kyushu University

Sano, Yoshiyuki

$\mathrm{R}$ and D Department, DIC Corporation

他

http://hdl. hand le. net/2324/26031

出版情報: Materials Letters. 64 (16)，pp.1793-1797，2010-08-31. Elsevier バージョン：

権利関係: (C) 2010 Elsevier B.V. 


\title{
Rapid synthesis of $\mathrm{Ag} @ \mathrm{Ni}$ core-shell nanoparticles using a microwave-polyol method
}

\author{
Masaharu Tsuji*a,b $^{\text {a }}$ Sachie Hikino ${ }^{a}$, Mika Matsunaga ${ }^{a}$, Yoshiyuki Sano ${ }^{c}$, \\ Tomoe Hashizume $^{\mathrm{d}}$, Hirofumi Kawazumi ${ }^{\mathrm{d}}$
}

a Institute for Materials Chemistry and Engineering, Kyushu University, Kasuga 816-8580, Japan

${ }^{\mathrm{b}}$ Department of Applied Science for Electronics and Materials, Graduate School of Engineering Sciences, Kyushu University, Kasuga 816-8580, Japan

${ }^{\mathrm{c}} R \& D$ Department, DIC Corporation, Sakura 285-8668, Japan

d Department of Biological and Environmental Chemistry, School of Humanity-oriented Science and Technology, Kinki University, Iizuka 820-8555, Japan

\section{ABSTRACT}

Mixtures of $\mathrm{AgNO}_{3}$ and $\mathrm{NiSO}_{4} \cdot 6 \mathrm{H}_{2} \mathrm{O}, \mathrm{NiCl}_{2} \cdot 6 \mathrm{H}_{2} \mathrm{O}$, or $\mathrm{Ni}\left(\mathrm{NO}_{3}\right)_{2} \cdot 6 \mathrm{H}_{2} \mathrm{O}$ were reduced in ethylene glycol (EG) in the presence of $\mathrm{NaOH}$ and poly(vinylpyrrolidone) (PVP) under microwave (MW) heating for $10 \mathrm{~min}$. Then, we succeeded in the synthesis of $\mathrm{Ag}$ core- $\mathrm{Ni}$ shell nanoparticles, denoted as Ag@Ni, in high yield. The formation of Ag@Ni particles was confirmed using energy dispersed X-ray spectroscopic (EDS) measurements and selected area electron diffraction (SAED) patterns. The growth mechanism of Ag@Ni is discussed. The UV-Vis spectra of Ag@Ni were similar to those of Ni particles. 


\section{Keywords:}

Core-shell structure

Microwave heating

Polyol method 


\section{Introduction}

Bimetallic nanoparticles have different electronic, optical, catalytic, and magnetic properties from those of individual metals. Therefore much attention has been received for the development of novel synthesis methods for bimetallic nanoparticles and their applications [1-7]. Among various nanoparticles, Ag-Ni bimetallic nanoparticles have attracted great attention due to their technologically important catalytic and magnetic properties [8-16]. Pronounced lattice mismatch, lower surface energy of $\mathrm{Ag}$, and importantly, the complete immiscibility between $\mathrm{Ag}$ and $\mathrm{Ni}$ make phase segregated core-shell structure the most thermodynamically stable for Ag-Ni stystem [8]. Simulations and calculation (e.g., DFT, global optimization, molecular dynamics, and Monte Carlo simulations) showed that Ni@ Ag core-shell structure is thermodynamically favorable [9-12]. Actually, Ni@ Ag nanoparticles have been synthesized from $\mathrm{Ag}_{2} \mathrm{SO}_{4}$ and $\mathrm{Ni}\left(\mathrm{NO}_{3}\right)_{2} \cdot 6 \mathrm{H}_{2} \mathrm{O}$ by Bala et al. by the foam based protocol using oleic acid as a protecting agent [15]. Chen et al. also synthesized Ni@Ag particles by the successive hydrazine reduction of $\mathrm{NiCl}_{2}$ and $\mathrm{AgNO}_{3}$ in $\mathrm{EG}$ without using protective agents or using polyethyleneimine as a protective agent [16].

Since an inverse $\mathrm{Ag} @ \mathrm{Ni}$ structure is thermochemically less stable than $\mathrm{Ni@Ag}$, little study has been carried out except for a recent pioneering work by Zhang et al. [13]. They prepared Ag@Ni using a two-step method. Initially monodispersed Ag seeds were synthesized from $\mathrm{AgNO}_{3}$ using oleylamine (OA) as a weak reductant. Then $\mathrm{Ni}$ atoms were controlled to grow upon the $\mathrm{Ag}$ seeds by controlling the decomposition of nickel 
acetylacetonate in OA. It took more than one day for the preparation of $\mathrm{Ag} @ \mathrm{Ni}$ in this two-step method. The main purpose of their study was controlling magnetic properties of $\mathrm{Ni}$ nanoparticles by non-magnetic Ag cores and the formation of Ag@ Ni was monitored only by contrast of TEM images and XRD measurements. No EDS and UV-visible (Vis) extinction spectral measurements were carried out, so that definite conclusion about crystal structures and optical properties were not obtained.

We have recently shown that a MW-polyol method is a rapid preparation method of metallic nanoparticles [17]. In the present study, we succeeded in the rapid one-pot synthesis of Ag@Ni particles in high yield using the MW-polyol method. The crystal structure of $\mathrm{Ag} @ \mathrm{Ni}$ particles and optical properties are determined on the basis of transmission electron microscopic (TEM)-EDS data, SAED patterns, and UV-Vis spectra.

\section{Experimental section}

After $0.08 \mathrm{mM} \mathrm{NiSO}{ }_{4} \cdot 6 \mathrm{H}_{2} \mathrm{O}, \mathrm{NiCl}_{2} \cdot 6 \mathrm{H}_{2} \mathrm{O}$, or $\mathrm{Ni}\left(\mathrm{NO}_{3}\right)_{2} \cdot 6 \mathrm{H}_{2} \mathrm{O}$ was dissolved in $17.75 \mathrm{~mL}$ EG solution in a $100 \mathrm{~mL}$ three-necked flask, $2.22 \mathrm{~g}$ of PVP (MW:55,000 in terms of monomer units) was added and dissolved. Then, $1 \mathrm{~mL}$ of $10 \mathrm{mM} \mathrm{AgNO}$ in $\mathrm{EG}$ and $1.25 \mathrm{~mL}$ of $400 \mathrm{mM}$ $\mathrm{NaOH}$ were added to the above solution. The reagent solution was heated under $\mathrm{MW}$ irradiation (reactor 400W) for $10 \mathrm{~min}$. The final concentrations of $\mathrm{Ni}$ salt, $\mathrm{AgNO}_{3}, \mathrm{PVP}$, and $\mathrm{NaOH}$ were $4 \mathrm{mM}, 0.5 \mathrm{mM}, 1 \mathrm{M}$, and $25 \mathrm{mM}$, respectively. The solution was heated to a 
boiling point of EG $\left(198{ }^{\circ} \mathrm{C}\right)$ after heating for about 2 min and then kept at this temperature for about $8 \mathrm{~min}$.

For TEM (JEM-2000XS and 2100F; JEOL) observations, samples were prepared by dropping colloidal solutions of the products onto $\mathrm{Au}$ grids after centrifugal separation. Extinction spectra of the product solutions were measured using a spectrometer (UV-3600; Shimadzu Corp.) in the UV-Vis region.

\section{Results and discussion}

When $\mathrm{NiSO}_{4} \cdot 6 \mathrm{H}_{2} \mathrm{O}$ was used as a reagent, color of solution changed to black before

heating. On the other hand, it changed

to black after heating when

$\mathrm{NiCl}_{2} \cdot 6 \mathrm{H}_{2} \mathrm{O}$ and $\mathrm{Ni}\left(\mathrm{NO}_{3}\right)_{2} \cdot 6 \mathrm{H}_{2} \mathrm{O}$ were

used. This indicates that the reduction

rate of $\mathrm{Ni}^{2+}$ in $\mathrm{NiSO}_{4} \cdot 6 \mathrm{H}_{2} \mathrm{O}$ is much

faster than that in the other two

reagents. Figs. 1a-1c depict typical

TEM images of product particles

obtained from the three reagents. (a)

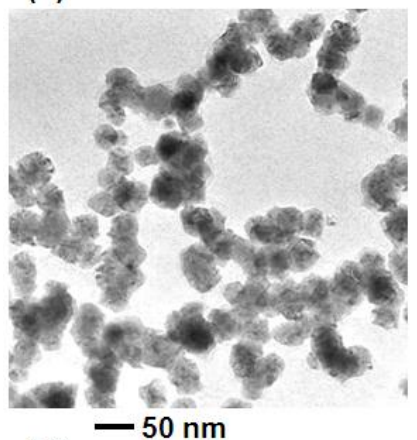

(c)

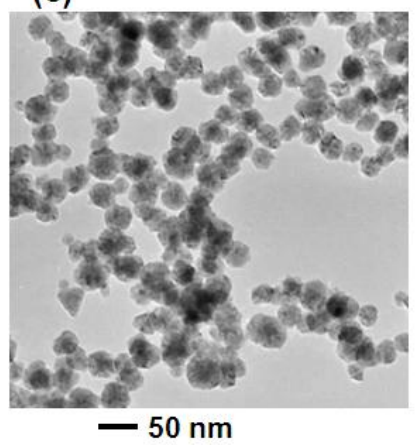

(b)

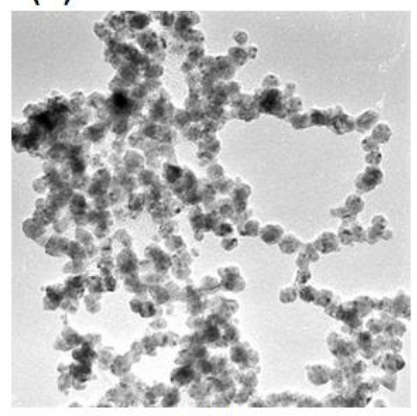

(d)

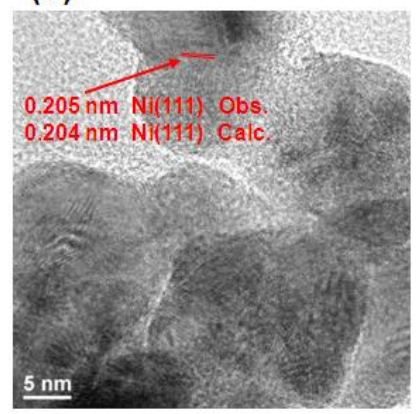

Fig. 1. TEM images of products obtained from mixtures of $\mathrm{AgNO}_{3}$ and (a) $\mathrm{NiSO}_{4} \cdot 6 \mathrm{H}_{2} \mathrm{O}$, (b) $\mathrm{NiCl}_{2} \cdot 6 \mathrm{H}_{2} \mathrm{O}$, or (c) $\mathrm{Ni}\left(\mathrm{NO}_{3}\right)_{2} \cdot 6 \mathrm{H}_{2} \mathrm{O}$. (d) HR-TEM of products using $\mathrm{NiCl}_{2} \cdot 6 \mathrm{H}_{2} \mathrm{O}$. 
sizes of $36 \pm 6,22 \pm 3$, and $33 \pm 4 \mathrm{~nm}$ were obtained from $\mathrm{NiSO}_{4} \cdot 6 \mathrm{H}_{2} \mathrm{O}, \mathrm{NiCl}_{2} \cdot 6 \mathrm{H}_{2} \mathrm{O}$, or $\mathrm{Ni}\left(\mathrm{NO}_{3}\right)_{2} \cdot 6 \mathrm{H}_{2} \mathrm{O}$, respectively. $\mathrm{Ni}(111)$ facets can be observed in the high resolution (HR)-TEM image (Fig. 1d and Fig. S1 in supplementary data), indicating that $\mathrm{Ni}$ nanocrystals exist outside of the product particles.

To obtain more information on the crystal structure, EDS analyses were made (Fig. 2). Although distinguishing between $\mathrm{Ag}$ and Ni component from the contrast of TEM images depicted in Figs. 1a-1c, 2a, $2 \mathrm{e}$, and $2 \mathrm{i}$ is difficult, EDS data indicate
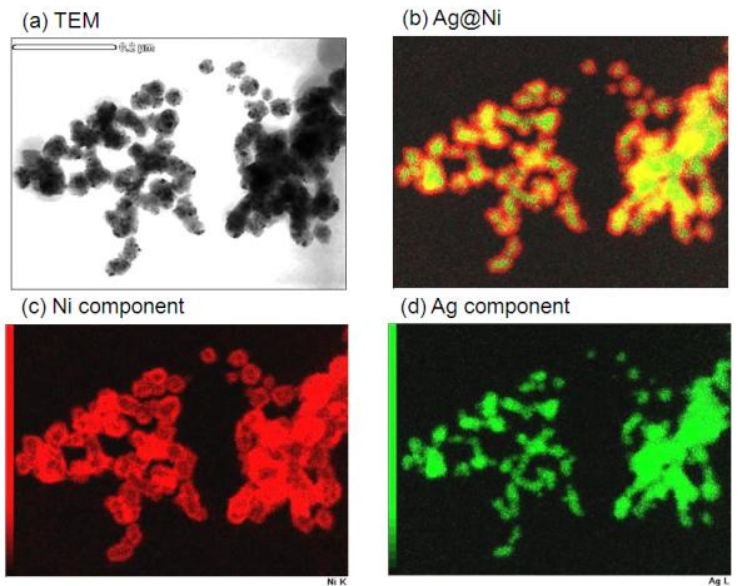

(d) Ag component
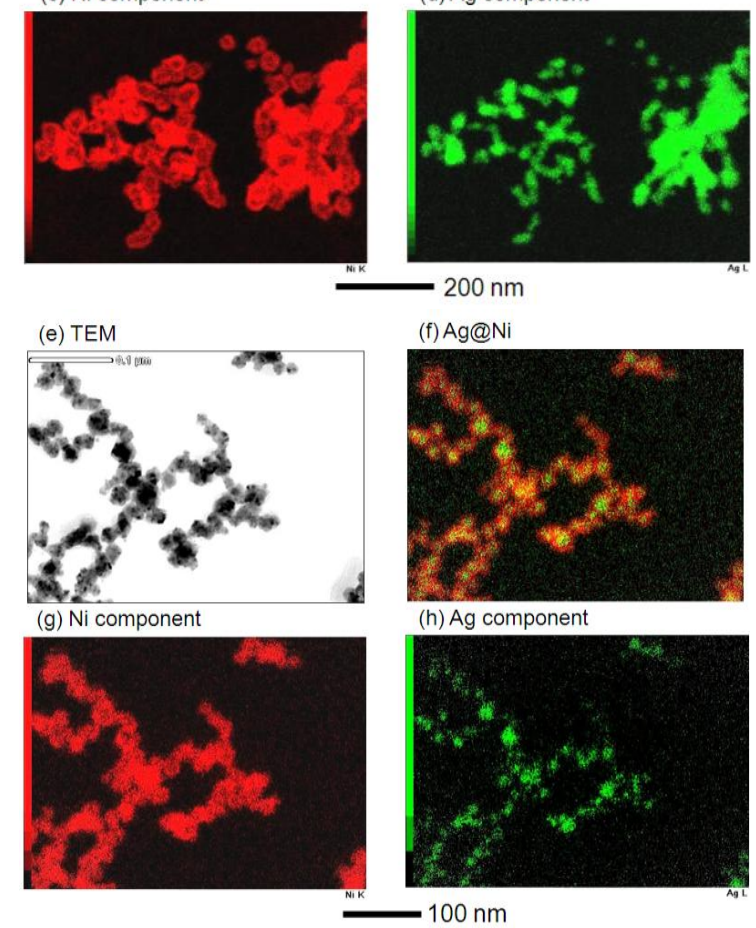

$200 \mathrm{~nm}$

that $\mathrm{Ag} @ \mathrm{Ni}$ core-shell particles are prepared in high yield $(100 \%)$. Here the yield was determined by counting the total numbers of $\mathrm{Ag} @ \mathrm{Ni}$ particles and evaluating their fraction in all products.

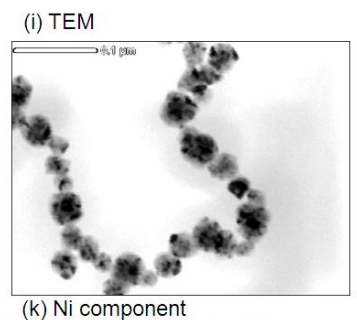
(j) Ag@Ni

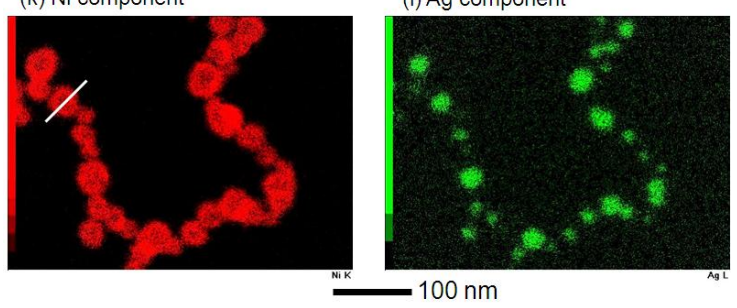

Fig. 2. TEM images and EDS data of products Some particles link together in all cases. obtained from mixtures of $\mathrm{AgNO}_{3}$ and (a-d) $\mathrm{NiSO}_{4} \cdot 6 \mathrm{H}_{2} \mathrm{O}$, (e-h) $\mathrm{NiCl}_{2} \cdot 6 \mathrm{H}_{2} \mathrm{O}$, or (i-l) Fig. 3 portrays distributions of the $\mathrm{Ag} \mathrm{Ni}\left(\mathrm{NO}_{3}\right)_{2} \cdot 6 \mathrm{H}_{2} \mathrm{O}$ under MW heating. 
and $\mathrm{Ni}$ components along the cross section

line of a typical particle shown in Fig. $1 \mathrm{k}$.

Similar line analysis data for several

particles implied that $12 \pm 1.7,7.5 \pm 0.96$, and

$9.4 \pm 1.2 \mathrm{~nm} \mathrm{Ni}$ shells were overgrown on

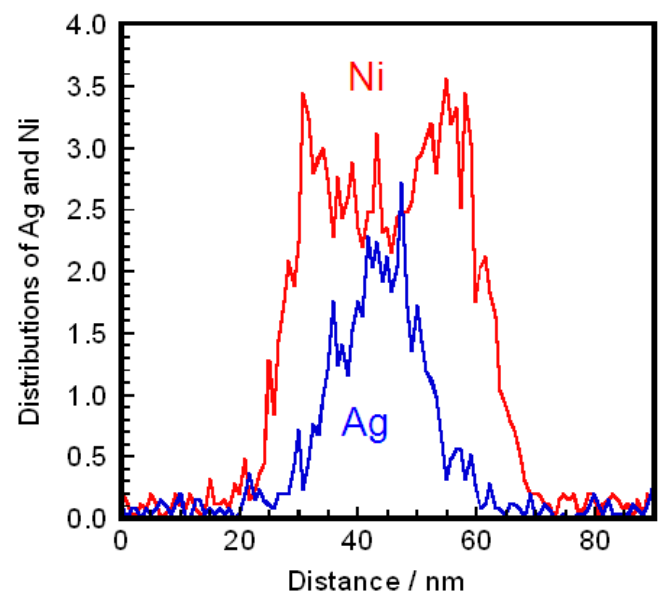

spherical Ag cores using $\mathrm{NiSO}_{4} \cdot 6 \mathrm{H}_{2} \mathrm{O}$,

Fig. 3. Distributions of $\mathrm{Ag}$ and $\mathrm{Ni}$ components in typical $\mathrm{Ag} @ \mathrm{Ni}$ particles $\mathrm{NiCl}_{2} \cdot 6 \mathrm{H}_{2} \mathrm{O}, \quad$ or $\quad \mathrm{Ni}\left(\mathrm{NO}_{3}\right)_{2} \cdot 6 \mathrm{H}_{2} \mathrm{O}$, along a line shown in Fig. 2k.

respectively. The atomic ratios of $\mathrm{Ag}: \mathrm{Ni}$

were determined to be $18: 82,14: 86$, and

$16: 85$, respectively for products obtained

using $\mathrm{NiSO}_{4} \cdot 6 \mathrm{H}_{2} \mathrm{O}, \quad \mathrm{NiCl}_{2} \cdot 6 \mathrm{H}_{2} \mathrm{O}, \quad$ or

$\mathrm{Ni}\left(\mathrm{NO}_{3}\right)_{2} \cdot 6 \mathrm{H}_{2} \mathrm{O}$, respectively. These results

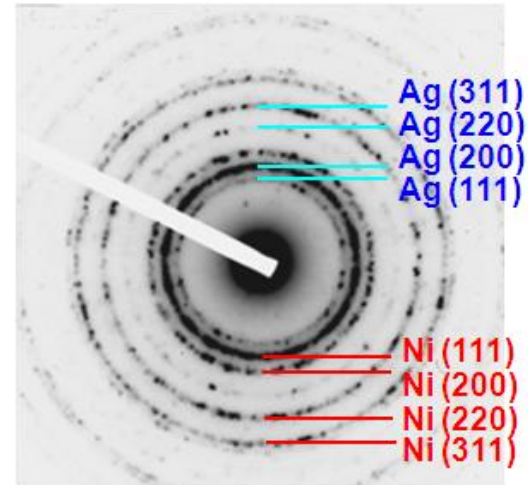

Fig. 4. SAED pattern of $\mathrm{Ag} @ \mathrm{Ni}$ particles prepared using $\mathrm{Ni}\left(\mathrm{NO}_{3}\right)_{2} \cdot 6 \mathrm{H}_{2} \mathrm{O}$.

imply that the product structures and Ag: $\mathrm{Ni}$ atomic ratios were essentially independent of the

Ni salt. An advantage of the present method is that monodispersed Ag@Ni particles can be prepared in one pot without using Ag seeds under MW heating for only 10 min.

We have also prepared Ag@Ni particles using a conventional oil-bath heating to examine effects of MW heating. For example, Ag@Ni particles obtained using $\mathrm{Ni}\left(\mathrm{NO}_{3}\right)_{2} \cdot 6 \mathrm{H}_{2} \mathrm{O}$ under oil-bath heating $(500 \mathrm{~W})$ is shown in Fig. S2 (supplementary data). Although Ag@ Ni particles can be prepared under oil-bath heating, it took at least 40 min to prepare Ag@ Ni. The average 
size of Ag@Ni and thickness of Ni shells were $57 \pm 17$ and $17 \pm 2.3 \mathrm{~nm}$, which were larger than those obtained under MW heating by factors of 1.7 and 1.8, respectively. These results imply that smaller particles having a narrow size distribution could be prepared in a short time under MW irradiation. Uniform heating of the reagent solution gives smaller monodispersed nanoparticles.

Fig. 4 shows a typical SAED pattern of Ag@Ni particle. We could observe many ED spots of (111), (200), (220), and (311) facets of Ag and Ni in SAED patterns. Similar patterns were obtained from the other two Ni reagents. It was therefore concluded that Ag@Ni particles are not amorphous but polycrystals having an fcc type of crystal structure. This finding is consistent with the HR-TEM data, where (111) facets of Ni were clearly observed.

$\mathrm{UV}-\mathrm{Vis}$ spectra were measured to characterize optical properties and to examine crystal growth of $\mathrm{Ag} @ \mathrm{Ni}$ particles (Fig. 5). For comparison UV-Vis spectra of typical spherical $\mathrm{Ag}$ and $\mathrm{Ni}$ particles in $\mathrm{EG}$ are also

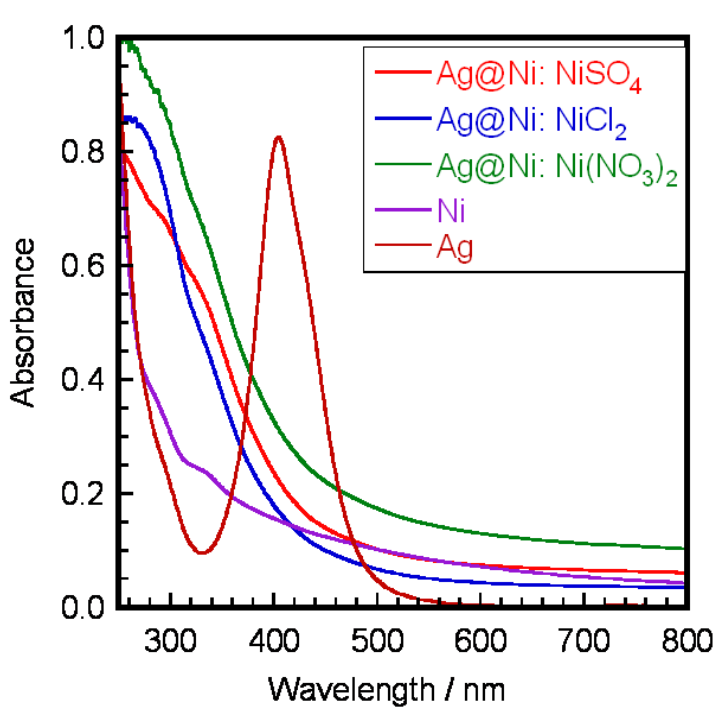

shown. Spherical Ag particles give surface plasmon resonance (SPR)

Fig. 5. UV-Vis spectra of $\mathrm{Ag} @ \mathrm{Ni}$ particles prepared from three $\mathrm{Ni}$ salts, $\mathrm{Ni}$, and spherical $\mathrm{Ag}$ bands with peaks at $\approx 400 \mathrm{~nm}$, whereas a weak continuous tail band is observed above $250 \mathrm{~nm}$ 
from Ni particles. The spectral features of Ni particles are similar to those reported previously [18]. The SPR bands of Ag@Ni are similar to that of Ni particles. On the other hand, it is known that the SPR band of Ni@Ag particles gives a similar SPR band due to Ag shell at $\approx 400 \mathrm{~nm}[15,16]$. These facts imply that the SPR bands of Ag@Ni and Ni@Ag reflect SPR characters of outer shells. This result is different from that of $\mathrm{Ag}-\mathrm{Cu}$ bimetallic system where both $\mathrm{Ag}$ and $\mathrm{Cu}$ or their mixed components appear in the SPR bands $[6,7,19]$.

On the basis of TEM-EDS and UV-Vis spectral data, it is reasonable to assume that $\mathrm{Ag} @ \mathrm{Ni}$ is grown through the following mechanism. Under the present fast MW heating, the crystal structure is not determined by thermochemical equilibrium of products but it is controlled kinetic factors such as reduction rates of $\mathrm{Ni}^{2+}$ and $\mathrm{Ag}^{+}$. Since the standard potential of $\mathrm{Ni}^{2+} / \mathrm{Ni}^{0}(-0.257 \mathrm{eV})$ is low, the reduction rate of $\mathrm{Ni}^{2+}$ is slow. Therefore, few $\mathrm{Ni}$ particles are formed without addition of strong reducing agent $\mathrm{NaOH}$, when $\mathrm{Ni}$ salts are reduced in $\mathrm{EG}$ in the presence of PVP. On the other hand, since the standard potential of $\mathrm{Ag}^{+} / \mathrm{Ag}^{0}(+0.799$ $\mathrm{eV}$ ) is relatively high, the reduction rate of $\mathrm{Ag}^{+}$is fast. Therefore, $\mathrm{Ag}^{+}$is reduced to $\mathrm{Ag}^{0}$ more rapidly than $\mathrm{Ni}^{2+}$ and $\mathrm{Ag}$ cores are initially formed.

We found that no $\mathrm{Ag} / \mathrm{Ni}$ alloys were formed in our conditions. One reason is that the reduction rate of $\mathrm{Ag}^{+}$is much faster than that of $\mathrm{Ni}^{2+}$ at $198{ }^{\circ} \mathrm{C}$. If $\mathrm{Ni}^{0}$ particles are formed through the reduction of $\mathrm{Ni}^{2+}$, they are oxidized again through the following spontaneous redox reaction in the presence of $\mathrm{Ag}^{+}$. 


$$
2 \mathrm{Ag}^{+}+\mathrm{Ni}^{0} \rightarrow \mathrm{Ni}^{2+}+2 \mathrm{Ag}^{0}
$$

This implies that $\mathrm{Ni}^{2+}$ ions are reduced after $\mathrm{Ag}^{+}$ions are completely reduced to $\mathrm{Ag}^{0}$. $\mathrm{This}$ is the other reason why $\mathrm{Ag} / \mathrm{Ni}$ alloys and $\mathrm{Ni@Ag} \mathrm{particles} \mathrm{are} \mathrm{not} \mathrm{formed} \mathrm{from} \mathrm{the} \mathrm{mixture} \mathrm{of}$ $\mathrm{Ag}^{+}$and $\mathrm{Ni}^{2+}$.

It is known that the reduction of $\mathrm{Cu}^{2+}$ is enhanced in the presence of silver nanoparticles [19]. This is due to the cathodic polarization of the $\mathrm{Ag}$ particles by electron transfer from organic radicals generated in the solution and subsequent reduction of $\mathrm{Cu}^{2+}$ directly on the surface of the Ag particles. A similar cathodic polarization of the Ag nanoparticles may occur in the present system, where some organic radicals and electrons are formed as intermediates in thermal decomposition of EG [17].

$$
\begin{aligned}
& \mathrm{CH}_{2} \mathrm{OH}-\mathrm{CH}_{2} \mathrm{OH} \rightarrow \mathrm{CH}_{3} \mathrm{CHO}+\mathrm{H}_{2} \mathrm{O} \\
& 2 \mathrm{CH}_{3} \mathrm{CHO} \rightarrow \mathrm{CH}_{3} \mathrm{COCOCH}_{3}+2 \mathrm{H}^{+}+2 \mathrm{e}^{-}
\end{aligned}
$$

The cathodic polarization of the Ag particles by electron transfer from organic radicals and by electron attachment on $\mathrm{Ag}$ particles may accelerate reduction of $\mathrm{Ni}^{2+}$ on $\mathrm{Ag}$ particles. This is another reason why $\mathrm{Ag} @ \mathrm{Ni}$ particles are preferentially formed from the mixture of $\mathrm{Ag}^{+}$and $\mathrm{Ni}^{2+}$.

\section{Conclusions}

We succeeded in the fast one-pot synthesis of monodispersed Ag@Ni particles in high 
yields from three Ni reagents using a MW-polyol method. Our result gave a new promising technique for the mass production of Ag@Ni particles. Although the core-shell structure of Ag@Ni particles was examined from the contrast of TEM images in a previous study [13], it was definitely confirmed by the TEM-EDS measurements in this study. The optical properties of $\mathrm{Ag} @ \mathrm{Ni}$ were similar to that of $\mathrm{Ni}$ nanoparticles, indicating that the shell component determines the optical properties in the Ag-Ni bimetallic system.

\section{Acknowledgements}

This work was supported by Grant-in-Aid for Scientific Research from the Japanese MEXT (No. 22310060). This work was performed under the Cooperative Research Program of "Network Joint Research Center for Materials and Devices (Institute for Materials Chemistry and Engineering, Kyushu University)".

\section{References}

[1] Toshima N. Pure Appl Chem 2000;72:317-25.

[2] Habas S, Lee H, Radmilovic V, Somorjai GA, Yang P. Nature Mater 2007;6:692-7.

[3] Majo KJ, De C, Obare SO. Plasmonics 2009;4:61-78.

[4] Tsuji M, Miyamae N, Lim S, Kimura K, Zhang X, Hikino S, Nishio M. Cryst Growth Des 2006;6:1801-7 
[5] Tsuji M, Matsuo R, Jiang P, Miyamae N, Ueyama D, Nishio M, et al. Cryst Growth Des 2008;8:2528-36.

[6] Tsuji M, Hikino S, Sano Y, Horigome M. Chem Lett 2009;38:518-9.

[7] Tsuji, M, Hikino, S, Tanabe R, Sano Y. Chem Lett 2009;38:860-1.

[8] Gaudry M, Cottancin E, Pellarin M, Lermé J, Arnaud L, Huntzinger JR, et al. Phys Rev B 2003;67:155409 (10 pages).

[9] Rossi G, Rapallo A, Mottet C, Fortunelli A, Baletto F, Ferrando R. Phys Rev Lett 2004;93:105503 (10 pages).

[10] Rapallo A, Rossi G, Ferrando R, Fortunelli A, Curley BC, Lloyd LD et al. J Chem Phys 2005;122:194308 (13 pages).

[11] Harb M, Rabilloud F, Simon D. J Phys Chem A 2007;111:7726-31.

[12] Calvo F, Cottancin E, Broyer M. Phys Rev B 2008;77:121406 (4 pages).

[13] Zhang HT, Ding J, Chow GM, Ran M, Yi JB. Chem Mater 2009;21:5222-8.

[14] Tang C, Li L, Gao H, Li G, Qiua X, Liub J. J Power Sources 2009;188:397-401.

[15] Bala T, Bhame SD, Joy PA, Prasad BLV, Sastry M. J Mater Chem 2004;14:2941-5.

[16] Chen DH, Wang SR. Mater Chem Phys 2006;100:468-471.

[17] Tsuji M, Hashimoto M, Nishizawa Y, Kubokawa M, Tsuji T. Chem Eur J $2005 ; 11: 440-52$.

[18] Tsuji M, Hashimoto M, Tsuji T. Chem Lett 2002;31:1232-3. 
[19] Jiang H, Moon KS, C. P. CP. 10th Int. Symp. Advpack. Mater: Process. Properties and Interfaces 2005:173-177.

\section{Supplementary data}

Expanded HR-TEM image of Fig. 1-d and Ag@Ni prepared under conventional oil-bath heating are given in supplementary data (http://www.sciencedirect.com). 


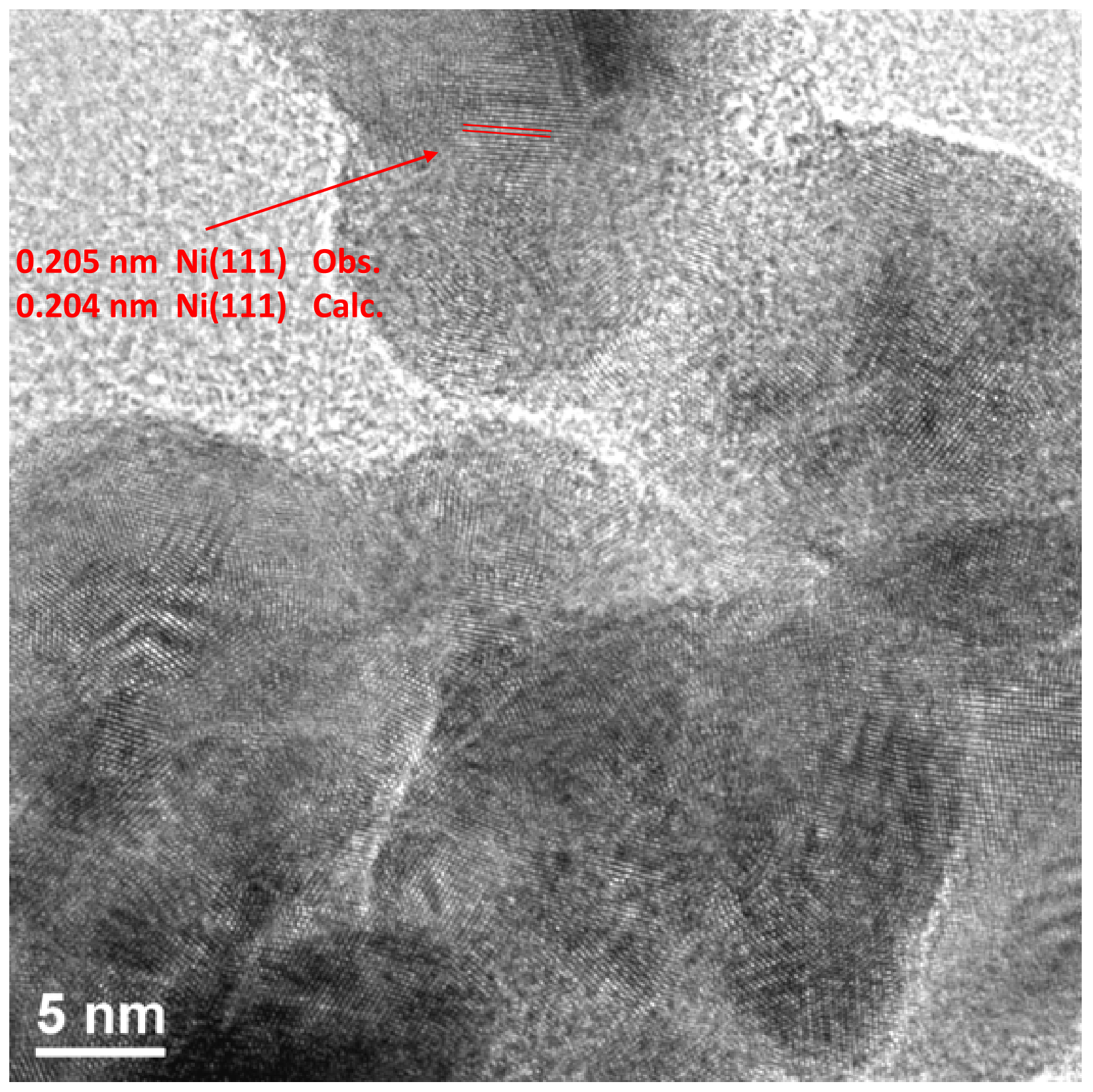

Fig. S1. Expanded HR-TEM image of Fig. 1d. 